\title{
Suicide in children and adolescents: $A$ case report of the possible suicide of a 7 year old girl and presentation of data from a forensic autopsy material in Norway.
}

\author{
Arne Stray-Pedersen M.D. Ph.D
}

Norwegian Institute of Public Health and University of Oslo, Department of Forensic Pathology and Clinical Forensic Medicine, Division of Forensic Medicine and Drug Abuse Research, Norway

\begin{abstract}
The present paper reports a 7 year old girl's death by hanging. The forensic investigation disclosed death most likely to be self-inflicted, either an act of suicide, subsidiary a case of accidental asphyxia from a child's play. A review of forensic autopsy records from southeast Norway during the years 1984-2012 was performed. Totally 116 deaths among children and adolescents < 18 years of age were classified as either suicide or as "undetermined - suicide likely" subsequent to post-mortem examination. The most common suicidal methods were hanging (46\%), the use of firearms (24\%), jumping in front of a train (11\%) and drug intake / intoxication ( $8 \%)$. Though rarely observed in children $<12$ years of age, suicide is a common cause of sudden death in adolescents, and there is evidence that the extent of the problem is unceasing. The paper highlights the value of forensic medical examination and crime scene reenactment in the evaluation of the manner of death in obscure cases.
\end{abstract}

Keywords:

Suicide, children, adolescents, reenactment, hanging

\section{CASE PRESENTATION}

An ambulance was called for a 7 year old girl who was found lifeless by her mother. The girl was allegedly hanging from a curtain pole. When the paramedics arrived a few minutes later the girl was not breathing and had no pulse. Although weak pulse was restored after cardiopulmonary resuscitation, later clinical and radiographic examinations showed signs of severe anoxic brain damage. The clinicians reported the observation of red marks on the girl's neck. After one week it was decided to turn off the ventilator and death occurred shortly after.

Present in the house at the time of the incident was only the girl, her mother and two younger siblings (aged $<2$ years old). The mother stated the girl had been alone in her room playing with some clothing only for a few minutes, while she was taking care of the smaller children in an adjacent room. She then found her daughter hanging from a long-sleeved nylon shirt, in which one sleeve was tightened around the girl's neck, the other sleeve attached to the curtain pole above the window in the room. The girl's father was away at work at the time of the incident. The family had immigrated to Norway from the Middle East a few years earlier. According to the mother, the girl had the previous day been watching a foreign channel TV show which put on view a romantic drama ending with a woman hanging herself from a tree.

\section{CLINICAL EXAMINATION AND AUTOPSY}

Clinical forensic examination performed three days after the incident revealed a constriction furrow on the anterior and lateral aspects of the neck. The furrow was $0.5-1.0 \mathrm{~cm}$ wide and slanted slightly upwards towards a point behind the right ear (Figure 1). A likely pattern of cloth was observed within the furrow. Neither petechial hemorrhages nor signs of facial congestion were observed. The subsequent post-mortem investigation disclosed remnants of the now brownish furrow, and anticipated anoxic brain damage and lung inflammation with diffuse alveolar injury due to ventilator therapy. No signs of body harm other than the constriction furrow were revealed.

The manner of death was ambiguous although the police interrogation did not disclose any findings suspicious of murder. The mother's story

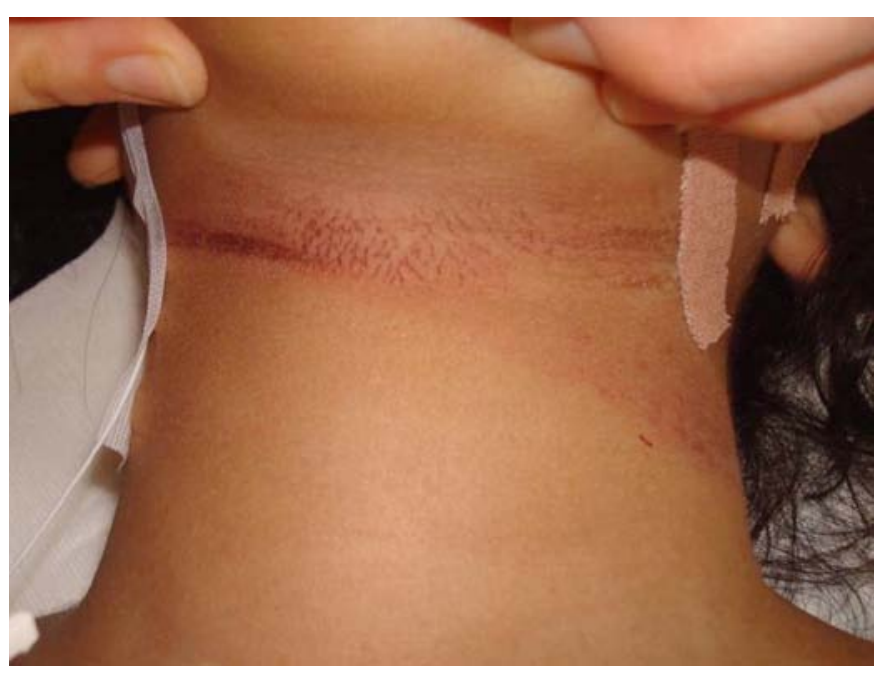

Figure 1. The constriction furrow. Note the abrasion marks beneath the furrow on the left side of the neck. 
indicated suicide by hanging, possibly a copycat action after watching suicidal behavior on TV. However the curtain pole was localized $210 \mathrm{~cm}$ above the floor and the girl had been barely $140 \mathrm{~cm}$ tall. An entirely selfinflicted arrangement was uncertain and an imposed strangulation (homicide) could not be ruled out.

\section{REENACTMENT OF THE SCENE}

A similar shirt and a doll were obtained prior to the reenactment performed by crime scene investigators from the police and a forensic pathologist. The purpose of the reenactment was to address the following questions:

- Is it conceivable for a child the size of the victim to tie a shirt around the curtain pole $210 \mathrm{~cm}$ above the floor?

- Is it conceivable for a child the size of the victim to tie the other sleeve of the shirt around her neck?

- Do both the curtain pole and the shirt withstand the strain of a hanging child the size of the victim?

The curtain pole showed signs of being recently twisted and its mounting bent where the shirt sleeve had been attached according to the mother.

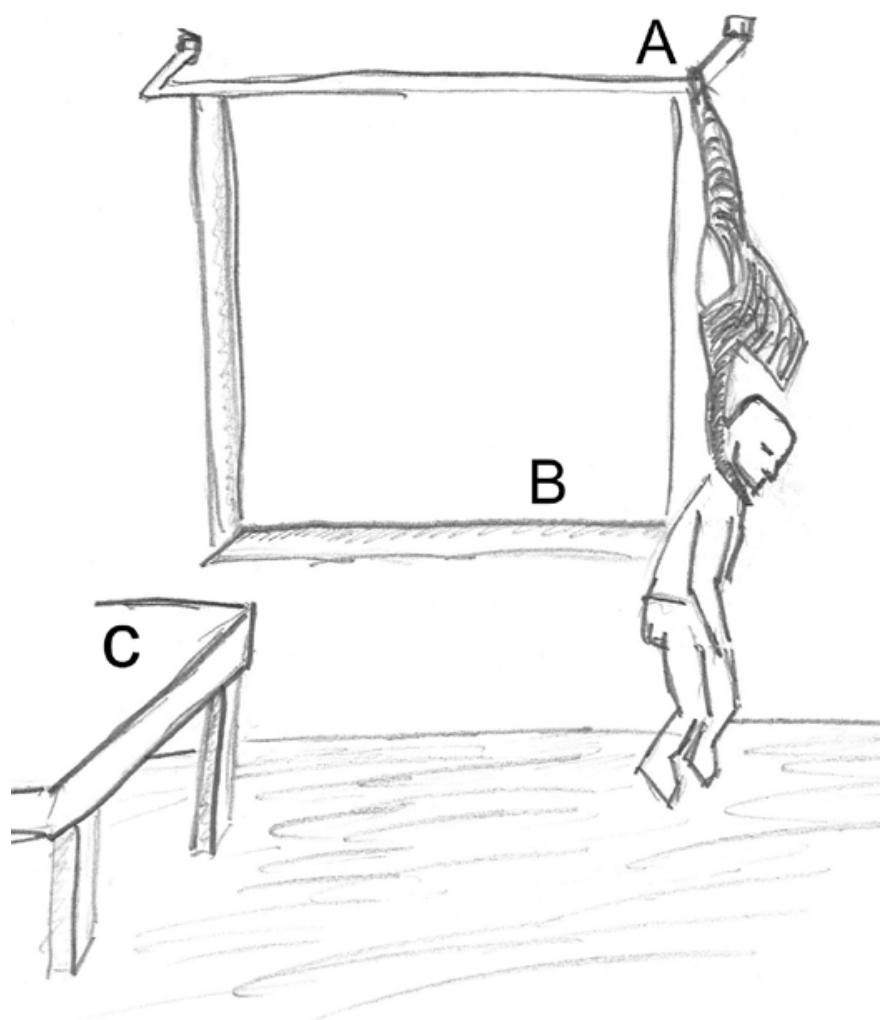

Figure 2. Outline of the death scene. The victim hung from the curtain pole (A) $210 \mathrm{~cm}$ above the floor. Signs of foot prints were observed on the lower frame (B), $125 \mathrm{~cm}$ below the curtain pole. The child may have used the table (C) to climb up to the window frame in order to tie the shirt to the pole.
To reach the curtain pole the child must have stood on the lower frame of the window, which was $85 \mathrm{~cm}$ above the floor, $10 \mathrm{~cm}$ deep and displayed probable footprints (Figure 2). A table in close proximity of the window may have been used for keeping balance. The table was too heavy for a child to move, thus she must have tied the shirt around the curtain pole with her arms at full stretch above her head. An attempt was performed guiding a sleeve of the shirt around the pole and securing the sleeve with a simple loose knot. Due to friction of the woven cotton fabric, the knot tightened easily when the shirt was pulled downwards. Thus it was concluded conceivable for the child single-handedly to tie the shirt around the curtain pole.

With the shirt hanging from the curtain pole, it was reenacted that a child the size of the victim could be able to tie the other sleeve once around the neck. Again, due to the friction of the cloth fabric, only moderate strain entirely fixed the sleeve around the doll's neck. The reenactment of the child's position when found lifeless by the mother is shown in Figure 3.

A load equal to the weight of the child was tied to the shirt sleeve and neither the pole nor the shirt broke apart. Thus the reenactment showed that the arrangement of hanging could indeed have been performed by the child alone.

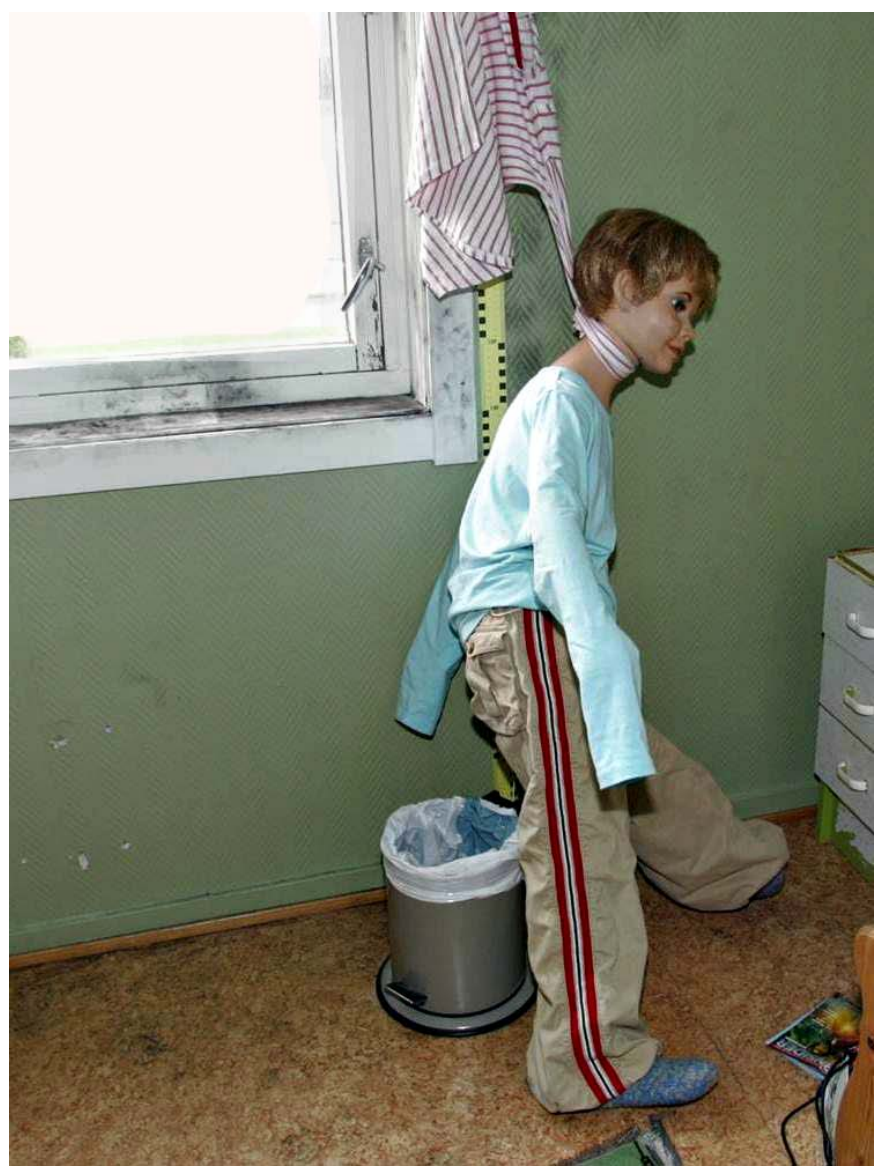

Figure 3. Reenactment of the position of the victim when found by the use of a plastic doll. 
(1)

\section{SUICIDE IN CHILDREN AND ADOLESCENTS - DATA FROM AUTOPSY FILES}

A review of the file registry of forensic autopsy reports at the National institute of Public Health (former Institute of Forensic Medicine) was performed. Data regarding the cause of death, manner of death, gender and the age of the victim was collected and statistically analyzed. Between 1984 and 2012 totally $116(M / F=87 / 29)$ children and adolescents aged 17 and below were by the forensic pathologist classified as either suicide, SNOMED FY3300 (106 cases) or as "undetermined - suicide likely" SNOMED FY3550 (10 cases). The methods of self-inflicted lethal injury were hanging (46\%), use of firearms (24\%), jumping in front of a train (11\%), drug intake / intoxication $(8 \%)$, drowning (5\%), jumping from height (4\%) and use of explosives (1\%). The presented case is the first victim less than 10 years of age and only a few cases of suicide in children aged 12 and under were observed. Suicide was more frequently observed with increasing age of adolescence (Figure 4). The number of child and adolescent suicides examined at the institute has decreased since 1984 (Figure 5).

\section{DISCUSSION}

Virtually all hangings are suicidal. Simulation of suicide by hanging a victim previously killed or made unable to resist by other means are regarded as extremely rare events. However, statistics may be deceptive in the evaluation of individual cases. The classic feature of hanging is the inverted-V configuration of the noose or other type of constriction band furrow. However, when the suspension is incomplete, the furrow may be less angled, especially when tightly fastened around the neck. In the present case, the constriction furrow was almost horizontal, slanting only slightly upwards toward the right side of the neck indicating the point of suspension. Abrasion marks observed beneath the furrow on the frontal left side of the neck may be explained by sliding of the cloth.

Most victims of hanging are obviously dead when being found, which allows the rope or other form of constricting band not to be cut from the

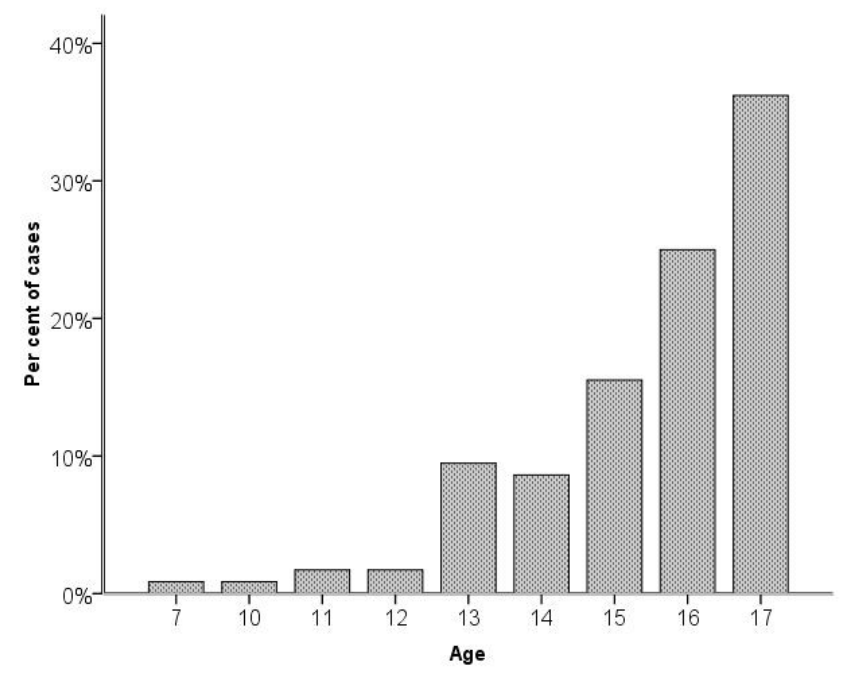

Figure 4. Age distribution of 116 child and adolescent suicides in southeast Norway 1984-2012. body prior to the examination by the forensic pathologist. When the victim survive (temporarily or permanently), early documentation of the external findings are important. Skin marks and petechial hemorrhages in the conjunctivae may disappear within few days and evidence lost when clinical forensic examination is not performed.

The present paper reports a possible suicide of a 7 year old girl. Although the manner of death to some extent remains ambiguous, the forensic medical examinations and the subsequent reenactment of the scene disclosed that a self-inflicted action is the most likely event. As the police interrogation furthermore did not disclose any findings suspicious of homicide, the case was dismissed by the prosecutor.

Suicide in a child less than 10 years of age has previously not been described in Norway. An Austrian study reported totally seven suicides nationally among children aged $5-9$ years in a thirty year period [1]. All died by hanging, which is the most common method of suicide in children and young adolescents in various countries [1,2]. The data presented in this paper indicate that suicide is a rare event in Norwegian children less than 13 years of age, but more common in adolescents. According to the National death registry, Statistics Norway, suicide is in fact the second most common cause of sudden death in adolescents next to traffic accidents (5). It has been argued that media coverage of suicides may influence suicide rates by an imitation effect [3]. Copycat suicidal attempts has also been reported in children [4]. In the present case the child had indeed watched suicidal behavior on TV shortly before being found dead. However the injurious event may not have been an act of self-destruction, but merely a part of a child's play. Thus it remains uncertain whether the death in fact was suicide or an accident.

The number of child and adolescent suicides examined at the institute has decreased since 1984 (Figure 5), with an average of 4.0 victims per year. However, National death registry data demonstrate no decrease in child and adolescent suicides in the same period, with an average of 17.5 deaths per year. Our institution covers approximately 3.0 mill people which accounts for around $60 \%$ of the population in Norway. The reduction in cases examined at the institute may thus be due to a reduction in the request of forensic

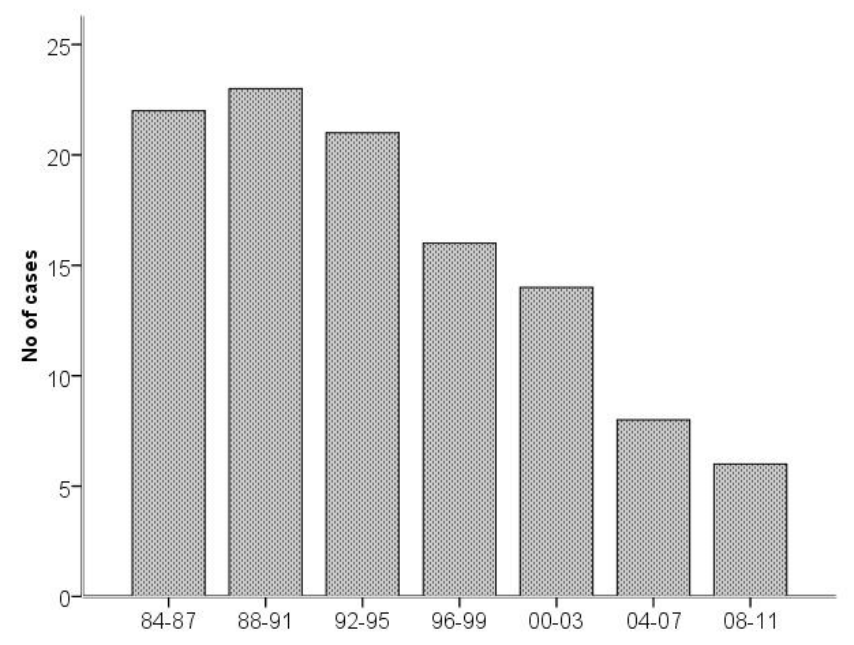

Figure 5. The number of child and adolescent suicides in four-year periods in southeast Norway, based on forensic autopsies during 1984-2011. 
post-mortem examinations by the police. In light of the presented case, lack of forensic examination is worrisome for a due process of law in such cases. Cases may incorrectly be mistaken for suicides, and others may result in false accusations of homicide. Any suicide in children and young adolescents are deep tragic events of enormous proportions for the relatives of the victim and remain a major challenge for the society.

\section{REFERENCES}

[1] Dervic K, Friedrich E, Oquendo MA, Voracek M, Friedrich MH, Sonneck G. Suicide in Austrian children and young adolescents aged 14 and younger. Eur Child Adolesc Psychiatry 2006; 15: 427-34.

[2] Hepp U, Stulz N, Unger-Koppel J, Ajdacic-Gross V. Methods of suicide used by children and adolescents. Eur Child Adolesc Psychiatry 2012; 21: 67-73.
[3] Stack S. Media coverage as a risk factor in suicide. J Epidemiol Community Health 2003; 57: 238-40.

[4] Ghanizadeh A. Copycat suicidal attempt by a 7 year old boy after watching homicidal behavior in media: a case report. Cases J 2009; 2: 43

[5] Statistics Norway. http://www.ssb.no/statistikkbanken/. Retrieved March 7, 2013 